\title{
Experience in Creating Learning Objects in a Professional Master's Degree in Education
}

\author{
Daiana Freitas Carpenedo, Jaline Gonçalves Mombach, Renato Xavier Coutinho, Marcele Teixeira \\ Homrich Ravasio, Ricardo Antonio Rodrigues, and Fábio Diniz Rossi
}

\begin{abstract}
The use of learning objects can be a transformer of traditional classrooms, driving the use of technology, and following the technological development experienced by students. However, the education of educators in Brazil does not offer the possibility of carrying out works with technologies that can aid the teaching and learning processes. This article presents an experience report based on a pedagogical practice suggested in a professional master's course in lecture area, where educators studied how to develop learning objects in the form of mobile applications and applied them on their own pedagogical practices. After, the students answered a questionnaire, and the answers allow us to discuss quantitatively and qualitatively the advantages and the effectiveness of such practice.
\end{abstract}

Index Terms-Education of educators, learning objects, mobile application, teaching.

\section{INTRODUCTION}

Contemporary students are experiencing the most intense period regarding stimulation from various technologies and sources. These are following a world where information permeates traditional models ubiquitously and pervasively. As such, educational institutions end up having the attention of such students split with several other platforms, such as smartphones, computers, television channels, and so on [1] [2]. However, while technology is available in many educational institutions, they are not widely used because of many issues, including low teacher compliance [3].

This scenario asks for a change of position on the maintenance of traditional teaching methodologies. New paradigms can drive this change, and meaningful learning based on the use of classroom technology is one of the most promising [4]. Several papers show successful research in including technologies in elementary education, providing the development of students' computational thinking. Rather, such actions as well as developing issues such as logic and reasoning, including teaching in the technological every day that the student is already inserted. Pedagogically speaking, such methodology consists of a path of change that focuses the teaching and learning processes directly on the student, allowing them to construct their knowledge by the support of orthogonal technologies to the more traditional models [5], [6].

However, the application of methodologies for meaningful

Manuscript received November 1, 2019; revised December 20, 2019

The authors are with Federal Institute of Education, Science and Technology Farroupilha, Brazil (corresponding author: Fábio Diniz Rossi; e-mail: fabio.rossi@iffarroupilha.edu.br). learning using technology is still quite insipid when we research its application in teacher training. However, there is still resistance from many educators in adopting new technologies in their pedagogical practices [7]. We could point out that this resistance is a natural process for change and that teachers' arguments are commonly related to their academic background. Many undergraduate courses do not provide the necessary workload for full training of teachers in the use of current technologies that aim to improve teaching and learning processes, leaving this specific practice, in the majority, in charge of postgraduate courses. For precisely from activity in such level course, this report of experience arises.

The professional master's degree courses have increased in Brazil, due to the characteristics of immediate application and objectives aimed at regional development, through the resolution of practical problems of a particular community. In particular, Capes (Coordination for the Improvement of Higher Education Personnel) teaching area has presented, in addition to growth, recognition due to the applicability of education theories, along with the problem-solving capacities that are fostered during the course. The professional master's degrees in the area of education are aligned with the challenges in teacher education, with the goals of the National Education Plan (PNE), and the National Postgraduate Plan (PNPG), which makes such courses the environment ideal for teacher practice connected to the use of technologies that generate new processes and technological products.

Among all the processes and products that can be developed in professional education masters, one of the most important is the creation of Learning Objects (LO) [8], which is defined as "any digital resource that can be used to support learning "and has reusability as a hallmark feature. In this way, the course develops theoretical knowledge about teaching and learning and allows this knowledge to be applied in the form of tools that assist such processes in the classroom [9].

In the context of professional masters, when we treat LO using technology such as software or mobile applications, each generated product equates regarding intellectual output to a $\mathrm{A}^{*}$ Article (http://www.core.edu.au), since it satisfies some premises, such as being registered as software in one an intellectual property regulator such as the National Institute of Intellectual Property (INPI http://www.inpi.gov.br/english), to be evaluated by a master's degree and available in a national or international institutional repository.

Based on what has been exposed previously, this 
experience report presents a practice performed during a master's degree in education, which aimed to develop LO in the form of applications for mobile devices. Each student created, based on his/her dissertation theme, a learning object during the period of the Educational Practices discipline, through a development environment for mobile applications with support to block programming, which abstracts and promotes the understanding of languages for non-computer students.

After completing the seminar, with the learning objects developed, a survey was applied, making it possible to enrich this experience report with a quantity-qualitative discussion that demonstrates that this may be a practice that can be replicated in other postgraduate programs that have the same characteristics, placing the students as active participants during the processes of ideation and implementation [10] as well as being an opportunity to raise the scores of the postgraduate program itself based on the criteria stipulated by Capes. Therefore, in this experience report, we present a theoretical framework that will serve as a basis for the understanding of the technologies involved, some quantitative and qualitative results, and a discussion about the feasibility of applying this practice, concluding with our conclusions and some future perspectives.

\section{BACKGROUND}

Currently, a new paradigm is being studied for the educational project. They are based on elements of a current of cognitive psychology that focuses on information processing involving sensory, operational, and permanent memories. In contrast, learning occurs only when the assimilation of knowledge goes through accommodation, the cognitive structure is reconfigured, and new traces are established for cognition. It is not a new Constructivism, but new ideas that include some constructivist principles [11]. Understanding that the students will not learn what does not interest and does not challenge them, the learning will be driven by the learner.

The focus is then shifted from teaching to learning, the student subject of the process, no longer passive receiver, where the teacher simply deposited knowledge in the student, a mere donation that had among its consequences the extermination of curiosity and creativity, when the goal of Education is to disturb the mind, not to calm it.

It emphasizes the development of cognitive skills and strategies that enhance them, valuing procedural knowledge (How to do? How to know?) And its contextualization (why, where, and when), replacing the still valued confessional Education (know that ...) [12]. However, it is increasingly evident that this implies a profound transformation in teaching practice, not only leading the learning process in a path of arousing curiosity, maintaining the foundation in the minimum content already mastered by students, but incorporating more technology in teaching.

Today we talk about learning objects, defined as digital or non-digital entities that can be used in teaching with technological supports, to organize and structure it. Although most commonly used in computer-based training systems and distance learning, any methodology that utilizes images, videos, or any other digital educational resource needs integrated planning from production through use to achieve the proposed objectives.

Educational experience has an essential agent of change in technology, and the way instructional material has been designed and implemented has a significant impact on the way we learn and fix content by incorporating it into prior knowledge. A useful learning object takes time and skill to build, from mastery of the theme to be worked on, choosing the best approach from a pedagogical point of view, proper management of the tool selected to assist the project and, especially, consistency during the execution of the project as a whole.

Although today we have a large number of applications, pre-recorded videos, digitized texts, and numerous multimedia resources available, teacher planning and student interest are essential to aggregate content while adhering to the educational proposal, once teaching and learning require active participation from all. If it is up to the teacher to strive to diversify how he makes information available, making it dynamic and meaningful to the students' world, it will be up to the active involvement, which can only happen if there is autonomy and willingness to produce and create, to discover new.

Despite the variety of technologies available in school colleges, we note that the teachers continue to write the contents of their lectures on a blackboard and the students copy them into their notebooks. For this to change, each teacher must find a comfortable way to gradually introduce technologies in teaching as a facilitating element of learning.

We can consider an advance that currently many schools have a computer lab with computers connected to the network. But using a computer lab or a video room involves the technical operation of these new technologies, and one of the obstacles for the teacher is to master these operations and the modern languages minimally.

The various information originated on the Internet in the form of texts and images implies mastery of the use, understanding, and use of these new languages and a new way of using them correctly. There are two large groups of teachers: some who risk using technology immediately but have not been trained to do so; The other group does not use the resources available because of insecurity in handling the appliance or application and/or for fear that the use of these features may result in the loss of their employment in the future. The teacher must lose fear; It can do with a digital application just as it interferes with written text, modifying it, adding new data, new interpretations, contexts closer to the student.

It is essential that the teacher does not feel threatened in his role as an intermediary and guides the student in this process and is challenged to break the barriers that prevent him from introducing technologies in the classroom in his daily life, in the face of concrete situations in teacher classroom: class sizes, large numbers of students, amount and duration of weekly classes and lack of institutional support.

\section{MATERIAL AND METHODS}

The practice presented in this experience report was 
carried out in a professional master's class in the education area, composed of 25 students, the majority of which are teachers working in the different administrative spheres: municipal, state, and federal. The major area of student instruction was diverse, none of which was computer literate. Therefore, a workshop for the development of digital learning objects was offered within a discipline of pedagogical practices, in the total period of 20 hour.

As smartphones are increasingly present in classrooms, we have chosen the MIT App Inventor (https://appinventor.mit.edu) programming platform, an open source development environment for Android applications, initially developed by Google and currently maintained by the Massachusetts Institute of Technology. Although it is a limited platform because the goal is to teach computational thinking to elementary education, it allows the development of simple applications, but that meet most of the needs of an LO. Also, the environment itself encourages reuse by providing a gallery of applications created in the tool and the remixes feature, which enables the editing of published applications, maintaining the authorship record and the improvements implemented by the community.

The language used by MIT App Inventor is block-based [13] which allows specifying algorithms and some sets of actions on the input data. Block language has a visual and intuitive appeal, considering that each block can be inserted only in spaces where logic makes sense. Currently, several development environments beyond MIT App Inventor use this programming model, such as Scratch, Blocky, Swift Playgrounds, among others. However, MIT App Inventor is a complete tool for creating end-user mobile applications in didactic-pedagogical contexts.

Based on this scenario, the practice of learning object development followed the order presented below:

1) Application introduction - introduces product-to-service paradigm shifts, current technology opportunities, which influences and impacts mobile applications on teaching practices.

2) Application development methodologies - presents the differences and characteristics of agile methods, Design Thinking, usability engineering cycles, elements of the user interface, lean UX, all of them discussed with user focus.

3) Knowledge acquisition theories - focus on the constructivism of [14], promoting a discussion about some basic methods, such as interactionism, socio-interactionism, and constructivism.

4) Introduction to the MIT App Inventor environment setting with the development interface, design mode and block mode, available components, features and possibilities for each element, blocks related to each component.

5) Logical and mathematical operators - theory and practice aimed at recalling logical operators, mathematical operators, operator precedence, conditionals, flow changes, and repetition.

6) Block programming and examples - the development of several small applications to present the behavior of the environment and the essential components used in the development of simple applications.
7) Repositories - introduction to different types of repositories, metadata and submission.

All phases presented are equally important. However, we would like to draw attention to step 3 . The main difference between an OA and any other mobile application is precise that LO is thought based on learning theory. As much as a didactic sequence in traditional models must have a clear objective regarding teaching and learning, OAs should also be thought about taking into account such goals.

The LO development practice was divided into three parts: ideation, implementation, and evaluation based on design thinking framework [15]. Implementation consisted of programming the applications, and evaluation was performed through the questionnaire that is presented and has the results discussed in this work. The ideation was guided by the dimensions of constructionism proposed by [14]. It allowed the LO developer to take an active stance in the development process, using information that gives meaning to the building of knowledge. This model goes against the instructional model, which uses the computer only as a teaching machine, with a passive attitude towards the information that is passed to it. Based on the above, there are five dimensions: pragmatic (useful immediately), syntactic (content according to relevance), syntactic (ease of use), semantics (meanings discovered with interaction) and social (the connection between social environment of the user).

In general, since the professional master's degree in education is focused on solving problems in local or regional communities which the master's degree is inserted, most of the learning objects were proposed and developed in two broad strands: didactic sequences that serve as an aid to some specific domain or as a survey to be answered by students aiming to store the data collected and analyze them for improvement in some institutional process.

After completing the course, a questionnaire was applied to the students of the master's degree so that we can analyze the feasibility and validity of the practice of learning objects development. To do so, we created a set of closed questions that show some quantitative results (1-5) and open-ended questions that will serve as the basis for a qualitative evaluation (6-7). Questions can be seen below:

1) Considering the short time in the workshop, how difficult is it to develop a learning object?

2) With the short workshop time, would you feel able to develop a simple learning object?

3) Have you ever thought about developing learning objects?

4) Do you believe that learning objects can improve classroom practice?

5) How do you evaluate intervention through a learning object?

6) Why do you rate the intervention like that?

7) What are the advantages that these mobile and tablet applications can bring to the classroom?

The next section presents the results collected in this questionnaire and discusses the answers in order to validate the practical proposal for the development of learning objects. 


\section{RESUlts}

The issues presented above were created with the intention of verifying the difficulty of developing mobile applications through the chosen development tool. Also, they enable participants to see participants' views on the purpose of applications as supporters in classroom activities. The questions were intended to reveal, in part, why teachers do not use learning objects in the classroom, and even why they do not develop their own didactic-technological materials.

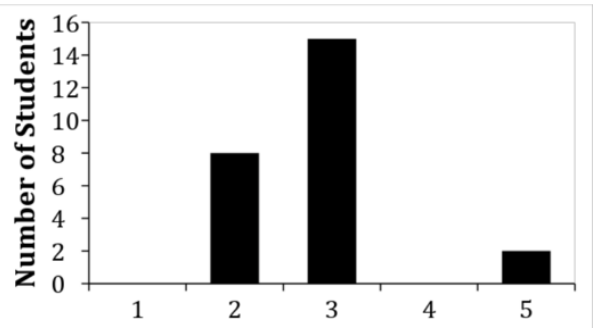

(1) Very Easy - (5) Very hard

Fig. 1. Level of difficulty in developing mobile applications.

The first issue concerns the difficulty in programming the software due to the short training time during the course, which consisted of the practice of 20 hours total. The answer offered a scale between 1 and 5 , is one equivalent to very easy, and five equivalent to very difficult. Each master's degree presented a different learning curve, and it was not expected that all could learn to program at the same time. It is a characteristic of absorbing that all teachers know, where each has their own time, depending on all their experiences, knowledge and skills. However, Fig. 1 shows that most of the masters converged for scores two and three answers (the three being the highest incidence).

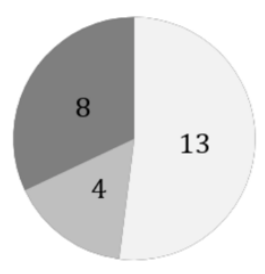

$\square$ Yes $\square$ No $\square$ Maybe

Fig. 2. Ability to develop a learning object based only on the knowledge taught in the discipline.

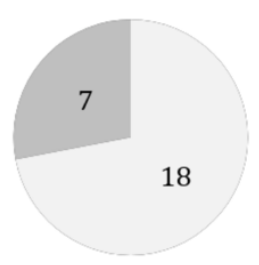

Yes $=$ No

Fig. 3. This chart shows the number of students who thought about developing learning objects, even before the course.

It means that most of the masters considered learning in MIT App Inventor comfortable or neutral. Maybe this happens due to blocking programming, and the results could be different pointing to a result of many difficulties when using programming languages like Java, among others.

The second question is whether the teacher was able to develop a simple learning object, even with the short time of discipline. According to the answers, Fig. 2 shows that $841 \%$ of the students answered that they feel able, or maybe they were able to develop learning objects, only with the skills worked during the course. The ease also influenced this response in developing mobile applications that MIT App Inventor provides to the developer.

The third question asks if the master student who is also a teacher, has already thought about developing some learning object, regardless of whether this is a mobile application. Fig. 3 shows that more than $70 \backslash \%$ of MS students had never thought about developing any type of learning object. It corroborates the idea that teacher education does not encourage the creation of pedagogical support tools or the use of technologies that can aid the teaching and learning processes. Thus, these teachers only reproduce the traditional model of education for which they were formed.

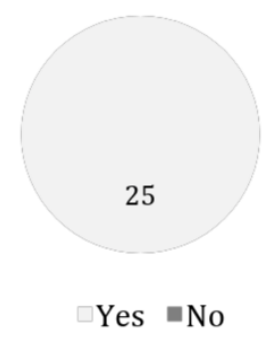

Fig. 4. All the students agree on the importance of learning objects in the classroom.

Although most master students have never thought about developing a learning object, all of them believe that such objects can improve classroom practice, as evidenced in answer to the fourth question presented in Fig. 4. What can we discuss about this is that teachers know that technology can influence the improvement of teaching and learning processes in the classroom, but due to the difficulties in changing the paradigm for which it was educated, apparently in most cases teachers prefer to maintain teaching more traditionally. It is important to emphasize that the answer shows that there is no ignorance of technology, teachers know the tooling that can be used, do not use it, perhaps because they think not being able.

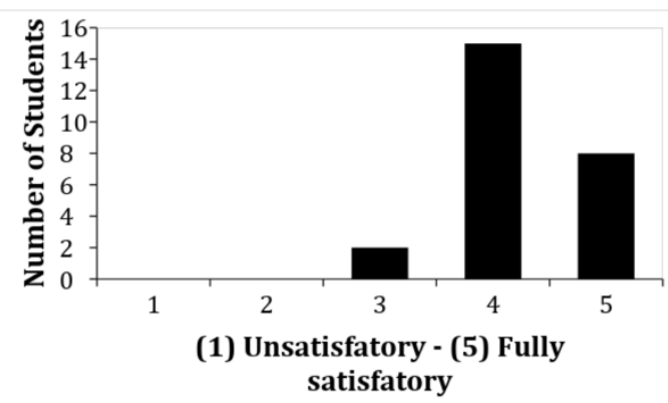

Fig. 5. View of the benefits of using learning objects in teaching.

The teachers' knowledge about the impact that the learning objects carry out on the teaching and learning processes can be seen in the answers of the fifth question represented in Fig. 5 .

On a scale between unsatisfactory (1) and very satisfactory (5), most of the masters' students scored the option satisfactory or very satisfactory. The reason for this question 
was the sixth question. Fig. 6 presents a word cloud on open question number six. As previously mentioned, there is full knowledge of the masters that learning objects, especially in the form of mobile applications, can bring the classroom closer to students due to the extensive use of various types of technology by the students.

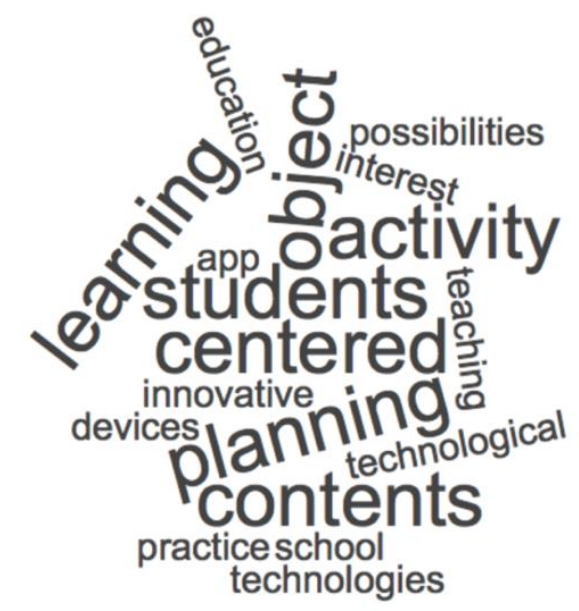

Fig. 6. A word cloud representing the opinion of the masters about why the importance of learning objects in the classroom.

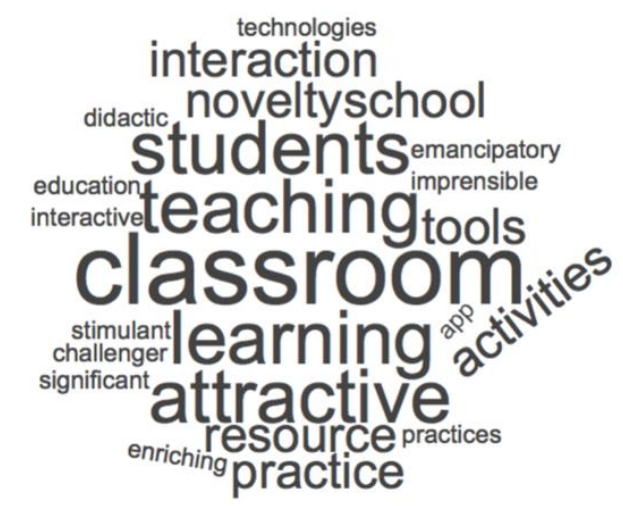

Fig. 7. A word cloud representing the opinion of the masters about the use of technologies as support in the classroom.

The last question does not necessarily relate to learning objects or mobile applications, but to the use of technological devices in the classroom. Fig. 7 shows that teachers understand that technology must be inserted in the school because it brings the student closer to his/her daily life and the rapid changes of the world, as well as providing a change in the way in which the contents can be approached.

Based on the presented results, we consider that this experience report brings a practice that can be replicated in any environment of teacher education so that future teachers can have experience in the development of educational technologies, especially the creation of learning objects in the form of mobile applications. Also, we bring some highlights on the advantages and difficulties in using such technologies in the school environment.

\section{DISCUSSION}

Reflecting on the ever-changing transformations brought about by the advancement of technology is essential, including to take full advantage of this new possibility in society. Children have early access to features such as computers, tablets, and smartphones. Why not bring different tools to the educational institution, providing new ways of learning, and attracting even more students' attention?

The challenge is to devise new ways of teaching, as using technology in the classroom does not mean abandoning books and traditional activities. But contact with new possibilities for carrying out the activities, since primary education, is fundamental for personal and professional growth, in a market that values specialized knowledge and professionals connected with the news.

The new tools stimulate the sharing of ideas and the exchange of experiences among all students. Relationships between students are strengthened with new opportunities, and the inclusion of students and teachers is encouraged as a whole in the learning process. In this regard, it is essential to remember the fundamental role of teachers to make the classes dynamic and profitable, bringing new methodologies, but without leaving behind the essentials, which is the importance of quality teaching.

As the focus is on students, deploying this model that unites the development of mobile applications in the form of learning objects provides greater autonomy concerning the topics that are addressed. Teachers can make their class schedule and set priorities within what they intend to teach. Meanwhile, students have more active learning. In this model, the teacher's role is to supervise what students are using in terms of technology and to guide them as to which paths to explore.

It is up to the teacher to provide content and materials that serve as the basis for classroom discussions within the learning objects. Thus, the tendency is for students to accumulate a more significant cultural and learning background and to question more about the content. It is a reflection of their autonomy in this format. After all, since it is up to them to actively practice the various technologies at their disposal, it is normal for them to deepen their research on the subjects that most interest them. The construction of this knowledge will be paramount for carrying out projects and academic research.

Another point of this model is that classes tend to be more participatory and less expository. Also, the relationships between students and teachers and between the students themselves become closer. With greater student participation, it becomes possible to identify the most significant questions and difficulties they are having, which makes a difference in the final tests.

We can summarize the greatest strengths of this practice in:

- Allows the teacher to show various ways of capture and show the same object, representing it under different angles and means by movements, scenarios, sounds, integrating the rational and the affective, the deductive and inductive.

- Facilitates student motivation, novelty, and endless possibilities for research.

- The teacher gets the student to develop cooperative learning, group research, exchange of results. The successful interaction increases learning.

- Emerges a need for continuing education to the teachers. To support teachers, so they can not only 
receive a new feature at school but also be able to know their potentialities and use them so that the process of teaching and learning.

- Provides means to update the quick knowledge, extend the educational spaces, expand opportunities where resources are scarce.

- In the unequal intimacy that students and teachers demonstrated by ICTs, there may be an effect beneficial because of every enthusiastic teacher to learn and do different students can associate more collaborative and supportive.

- The opportunity to be in touch, even if virtual, with communities in other states or even can facilitate young people to understand and accept different realities, cultures, and ways of life than theirs.

- Shifting emphasis from the formal and impersonal curriculum for lively and exciting exploration by students.

Regarding the list of fortresses presented, it is clear that educational technologies facilitate the student's teaching and learning, making them more easily motivated to learn, because the student is already inserted in a technological world, creating a class with a technical educational methodology is a differential for the understanding of specific contents by this connected young.

In addition to motivation, teachers have many possibilities to present their syllabus, from other angles and perspectives, making abstract content become a palpable and easy to understand the content, and can insert students in different realities experienced by them., facilitating the understanding of other cultures or ways of life separate from your daily life. It is perceived as a means of broad knowledge, where the teacher can expand their educational space, where often it could be challenging to obtain the teacher because their opportunities and resources are scarce.

In addition to teaching, the educator can create a beneficial effect of exchange with his students, as the teacher will often be in constant learning with his students, realizing that technologies besides facilitating teaching can bring an impact of bringing students closer to it is in the classroom, thus creating more collaborative students at the school, making a formal and impersonal curriculum a curriculum for living exploration and exciting for students.

\section{CONCLUSION}

There is a new generation of students who grew up using various digital resources. It means that they can absorb and apply new technologies more naturally than all other ages, mix real and virtual communities, and have greater control over information flow, overload, and discontinuity. In a fully connected world where information is at a click away, models of teaching based on purely empirical learning theories still try to keep the attention of these students in the classroom [16] Worse than that, some teachers, based on these traditional models, forbid the use of classroom technology.

Traditional models of teaching present a series of limitations, such as they do not support or update the amount of data as distributed in several channels of information in real time, do not update their pedagogical tool with news that is accessible and enough used by the students, and do not accompany the worldwide movement towards more flexible and affordable education to anyone and everywhere [17], [18]. Therefore, they do not prepare students for the real world.

Therefore, we have a scenario of students, who are daily connected to a technological world and directed to computational thinking, and teachers who will in future mediate teaching and learning processes but does not have in their teacher training a minimum dedicated to the use and production of technologies to support pedagogical practices. Due to this, this experience report presents an educational activity carried out in a professional master's degree in the area of education aiming at the creation of learning objects. This course focuses on the development of processes or products aimed at solving constraints found locally or regionally, in the communities or institutions where the masters are enrolled.

The development of learning objects is not only relevant to solving such issues but also academically important regarding academic production. Provided that such learning objects are registered as software in an intellectual property body, passed through the analysis of a bank, and available in a national or international institutional repository, each learning object is equivalent to a $\mathrm{A}^{*}$ article in the area of education of Capes. Thus, the proposal presented in this article can perhaps be used as a standard by professional graduate programs in the teaching field or other areas that punctuate them in the same way.

As most masters' students are teachers, we have been able to see in the evaluations that prevailing opinion that learning objects are attractive resources, which capture students' attention. Also, it is a resource that can be stimulating, challenging, provocative and that allows dynamics never before experienced in a school environment. The school must be oriented not to alienate students from the technologies, but to use these to facilitate their purpose of educating. In this way, the objects of learning are shown as a current tool and indispensable for those who propose to offer a comprehensive and emancipatory education to their students.

One of the results that must be retaken into account is the impression that masters' students could never develop learning objects in the form of mobile applications (before performing the proposed practice). Perhaps this is the feeling of most teachers who still do not use technologies in the classroom, while still retaining traditional teaching models or methodologies. It is up to this type of practice to demystify this apparent difficulty, and to show that using appropriate computational tools (MIT App Inventor abstracted most programming difficulties from traditional software development environments, boosting creativity and allowing rapid development of simple mobile applications), anyone can develop their didactic sequences, which will undoubtedly improve students' interest in the applied domain.

\section{CONFLICT OF INTEREST}

The authors declare no conflict of interest. 


\section{AUTHOR CONTRIBUTIONS}

D. F. Carpenedo participated in all phases of the proposal, from teaching the class to students, applying the questionnaire, and evaluating the results. J. G. Mombach, F. D Rossi, and R. X. Coutinho taught the course to the students. M. T. H. Ravasio and R. A. Rodrigues applied the questionnaire and analyzed the results. All authors wrote and reviewed the article cooperatively.

\section{REFERENCES}

[1] L. Corrin, L. Lockyer, and S. Bennett, "Technological diversity: An investigation of students' technology use in everyday life and academic study," Learning, Media and Technology, vol. 35, no. 4, 2010, pp. $387-401$.

[2] J. M. Lloyd, L. A. Dean, and D. L. Cooper, "Students' technology use and its effects on peer relationships, academic involvement, and healthy lifestyles," NASPA Journal, vol. 46, no. 4, 2009, pp. 695-709.

[3] J. B. Carroll and P. D. Morrell, "A comparison of teacher education faculty and preservice teacher technology competence," Journal of Computing in Teacher Education, vol. 23, no. 1, 2006, pp. 5-10.

[4] D. E. M. Willis and D. G. R. Tucker, "Using constructionism to teach constructivism," Journal of Computing in Teacher Education, vol. 17 no. 2, 2001, pp. 4-7.

[5] L. A. Mesiti, A. Parkes, S. C. Paneto, and C. Cahill, "Building capacity for computational thinking in youth through informal education," Journal of Museum Education, vol. 44, no. 1, 2019, pp. 108-121.

[6] J. A. Rodríguez-Martínez, J. A. González-Calero, and J. M. Sáez-López, "Computational thinking and mathematics using scratch: an experiment with sixth-grade students," Interactive Learning Environments, 2019, pp. 1-12.

[7] Y. Liu and C. Huang, "Concerns of teachers about technology integration in the USA," European Journal of Teacher Education, vol. 28, no. 1, 2005, pp. 35-47.

[8] T. Koppi, L. Bogle, and M. Bogle, "Learning objects, repositories, sharing and reusability," Open Learning: The Journal of Open, Distance and e-Learning, vol. 20, no. 1, 2005, pp. 83-91.

[9] F. Alonso, G. López, D. Manrique, and J. M. Viñes, "Learning objects, learning objectives and learning design," Innovations in Education and Teaching International, vol. 45, no. 4, 2008, pp. 389-400.

[10] G. Ceviker-Cinar, G. Mura, and M. Demirbag-Kaplan, "Design thinking: A new road map in business education," The Design Journal, vol. 20, no. sup1, 2017, pp. S977-S987.

[11] D. Cavallo, S. Papert, and G. Stager, "Climbing to understanding: Lessons from an experimental learning environment for adjudicated youth," in Proc. the 6th International Conference on Learning Sciences, ICLS '04, International Society of the Learning Sciences, 2004, pp. 113-120.

[12] D. Carr-Chellman, "Freirean principles for e-learning," eLearn, 2016.

[13] B. Jiang, W. Zhao, N. Zhang, and F. Qiu, "Programming trajectories analytics in block-based programming language learning," Interactive Learning Environments, 2019, pp. 1-14.

[14] S. Papert and I. Harel, "Situating constructionism," Constructionism, Ablex Publishing Corporation, Norwood, NJ, 1991, ch. 1.

[15] L. Kimbell, "Rethinking design thinking: Part i," Design and Culture, vol. 3, no. 3, 2011, pp. 285-306.

[16] D. Grewal, A. Roggeveen, and R. C. Runyan, "Retailing in a connected world," Journal of Marketing Management, vol. 29, no. 3-4, 2013, pp. $263-270$.

[17] E. Terhart and H. Drerup, "Knowledge utilization in the science of teaching: Traditional models and new perspectives," British Journal of Educational Studies, vol. 29, no. 1, 1981, pp. 9-18.
[18] T. Teo and M. Zhou, "The influence of teachers' conceptions of teaching and learning on their technology acceptance," Interactive Learning Environments, vol. 25, no. 4, 2017, pp. 513-527.

Copyright $\odot 2020$ by the authors. This is an open access article distributed under the Creative Commons Attribution License which permits unrestricted use, distribution, and reproduction in any medium, provided the original work is properly cited (CC BY 4.0).

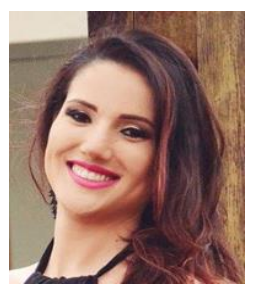

Daiana Freitas Carpenedo is auditor at Federal Institute of Education, Science and Technology Farroupilha, Brazil. She got the MSc in professional and technological education. Her research interests include the ethics in research and education.

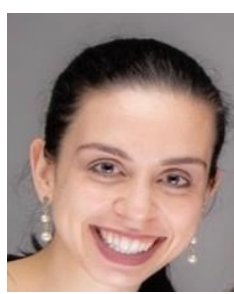

Jaline Gonçalves Mombach is professor at Federal Institute of Education, Science and Technology Farroupilha, Brazil. She got the MSc in electrical engineering. Her research interests include the interplay between computing and education.

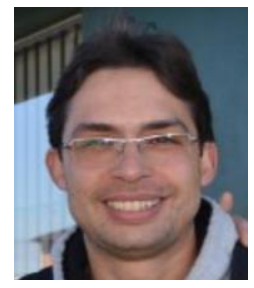

Renato Xavier Coutinho is professor at Federal Institute of Education, Science and Technology Farroupilha, Brazil. He got the $\mathrm{PhD}$ in science teaching. His research interests include the professional and technological education.

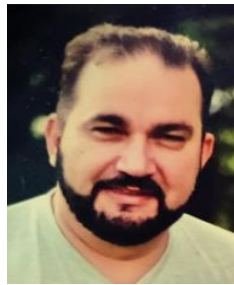

Ricardo Antonio Rodrigues is professor at Federal Institute of Education, Science and Technology Farroupilha, Brazil. He got the PhD in philosophy. His research interests include the professional and technological education.

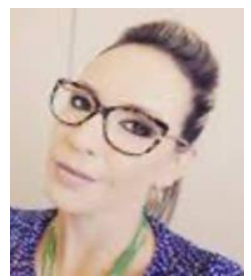

Marcele Teixeira Homrich Ravasio is professor at Federal Institute of Education, Science and Technology Farroupilha, Brazil. She got the $\mathrm{PhD}$ in education. Her research interests include the professional and technological education.

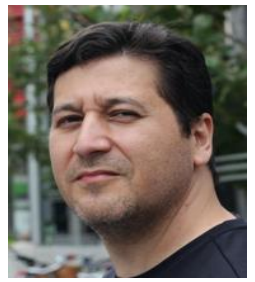

Fábio Diniz Rossi is professor at Federal Institute of Education, Science and Technology Farroupilha, Brazil. He got the $\mathrm{PhD}$ in computer science. His research interests include the interplay between computing and education. 